\title{
Chronic hepatic porphyria
}

INSERM

\section{Source}

INSERM. (1999). Orphanet: an online rare disease and orphan drug data base. Chronic hepatic porphyria. ORPHA:95161

Chronic hepatic porphyrias represent a sub-group of porphyrias (see this term). They are characterized by bullous photodermatitis caused by a deficiency of uroporphyrinogen decarboxylase (URO-D; the fifth enzyme in the heme biosynthesis pathway). Chronic hepatic porphyria encompasses two diseases: porphyria cutanea tarda and hepatoerythropoietic porphyria (extremely rare) (see these terms). 